Paper

\title{
High Temperature Hardness and Wear Resistance of Alumina-Dispersed High-Chromium Cast Iron PM alloys Prepared by the MA-SPS Process
}

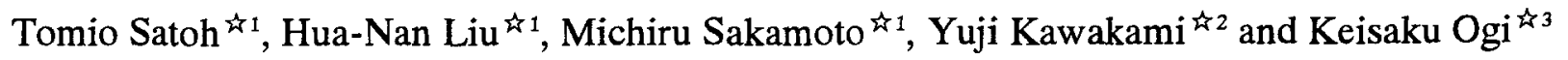 \\ Institute for Structural and Engineering Materials, National Institute of Advanced Industrial Science and Technology, 807-1 Shuku, Tosu 841-0052. \\ ${ }^{2}$ Industry Technology Center of SAGA, 114 Yaemizo, Nabeshima, Saga 849-0932. \\ मे ${ }^{3}$ Kyushu University, 6-10-1 Hakozaki Higashi-ku, Fukuoka 812-0051.
}

Received August 1, 2003

\section{SYNOPSIS}

The MA-SPS (mechanical alloying followed by spark plasma sintering) process was adopted to further improve the high temperature properties of a newly developed $36 \mathrm{Cr}$ white cast iron (a eutectic $\mathrm{Fe}-36 \mathrm{Cr}-9 \mathrm{Ni}-5 \mathrm{Mo}-0.45 \mathrm{Si}$ 2.2C alloy). $\alpha-\mathrm{Al}_{2} \mathrm{O}_{3}$ powder with a mean diameter of $0.4 \mu \mathrm{m}$ was used as reinforcement for the MA material, and the volume fractions of $\mathrm{Al}_{2} \mathrm{O}_{3}$ in the composites were $10 \%$ and $30 \%$. The results show that the microstructures of the MA materials were greatly refined compared to those of the conventionally solidified ingot and that their high temperature hardness and high temperature abrasive resistance were considerably improved. Also found was that the increase in the volume fraction of the $\mathrm{Al}_{2} \mathrm{O}_{3}$ powder increased both the hardness and the abrasive resistance of the composite materials.

\section{KEYWORDS}

alumina-dispersed high-chromium cast iron, mechanical alloying, spark plasma sintering, high temperature hardness, high temperature abrasion resistance

\section{Introduction}

High $\mathrm{Cr}$ white cast irons (HCWCIs) containing a large amount of carbides with high hardness are commonly used for wear resistant applications in the mining and minerals industries, steel making plants, etc. ${ }^{1)}$. The excellent wearresistance of these materials results mainly from the hard carbides dispersed in an austenite matrix. Generally, the HCWCIs are designed to consist of a strengthened austenite matrix with uniformly dispersed hard carbides. In recent studies, we have successfully developed a eutectic $36 \mathrm{Cr}$ cast iron which exhibits excellent wear- and oxidationresistance at elevated temperatures ${ }^{2}$. In the present study, mechanical alloying followed by spark plasma sintering (MA-SPS) process and the composite technique are adopted to further improve the high temperature properties of this newly developed material. This paper describes the hardness, abrasion resistance of both the MA materials and its composites at elevated temperatures.

\section{Experimental procedure}

The eutectic $36 \mathrm{Cr}$ alloy employed had a chemical composition of $\mathrm{Fe}-36 \mathrm{Cr}-9 \mathrm{Ni}-5 \mathrm{Mo}-0.45 \mathrm{Si}-2.2 \mathrm{C}$ (mass\%), and the reinforcement was the $\alpha-\mathrm{Al}_{2} \mathrm{O}_{3}$ powder with a mean diameter of $0.4 \mu \mathrm{m}$. As shown in Fig. 1, the fabrication process of the MA materials was: pre-mixing the element powders with the $\mathrm{Al}_{2} \mathrm{O}_{3}$ powder (the volume fractions of the $\mathrm{Al}_{2} \mathrm{O}_{3}$ powder were 0,10 and $30 \%$ ) using a $\mathrm{V}$-type blender for homogeneous dispersion of each powder followed by the MA process with a planetary-type ball mill for $200 \mathrm{~h}$ in argon atmosphere, and then consolidation by spark plasma sintering at $1373 \mathrm{~K}$ by uniaxial pressing at $50 \mathrm{MPa}$ to form coin-shaped specimens $(\phi 32 \times 6 \mathrm{~mm})$. The conventionally solidified $36 \mathrm{Cr}$ ingot and a widely used hypoeutectic $25 \mathrm{Cr}$ cast iron ingot (Fe-25Cr-0.5Ni-0.5Mo-2.9C) were also

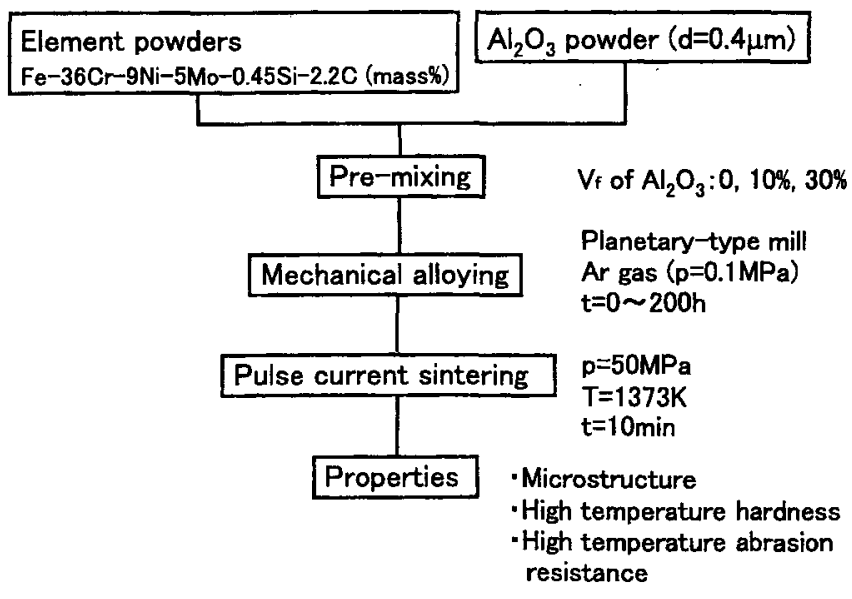

Fig.1 Fabrication procedure of MA materials. 
prepared for comparison.

The structure of the mixed powders at different MA times was analyzed with an X-ray diffractometer. The Vickers hardness of the test materials was measured at room temperature, $773,873,973$ and $1073 \mathrm{~K}$ under a load of $49 \mathrm{~N}$ in argon gas atmosphere. The high temperature wear test was performed using a newly designed low stress abrasive tester described elsewhere ${ }^{3)}$. This tester consists of a symmetric $\Pi$-shaped specimen holder that is rotated in a stainless steel tank filled with silica sand (average particle size $=1 \mathrm{~mm}$ ), and an electrical furnace surrounds the tank to heat the abrasive sands, as shown in Fig. $2^{3)}$. The testing materials and its comparative sample ( $25 \mathrm{Cr}$ cast iron ingot), of a size of $20 \times 20 \times 5 \mathrm{~mm}$, were placed at the respective branches of the holder, leaving a $20 \times 20 \mathrm{~mm}$ face of each specimen to be exposed to abrasion. During the experiments, the rotation speed of the specimen holder was $200 \mathrm{rpm}$ (the specimens' speed was $1.36 \mathrm{~m} / \mathrm{s})$, the wearing time for each measurement of the mass loss was $20 \mathrm{~h}$ (the total wearing time was $80 \mathrm{~h}$ ), and the testing temperature was $923 \mathrm{~K}$. The silica sand was exchanged with new material every $20 \mathrm{~h}$. The final results of the abrasion test were given by the volume loss of the specimens as a function of the wearing time.

\section{Results and discussion}

The XRD patterns of the elements during the MA process of the $36 \mathrm{Cr}$ composition specimen are shown in Fig. 3. It shows that the peak of the $C$ element disappears at the very early stage of the MA process (within 5-h MA time), showing the solution of $\mathrm{C}$ in the $\mathrm{Fe}$ and/or $\mathrm{Cr}$, while the peaks of the $\mathrm{Ni}$ and Mo elements disappear at the later stages. At the 100-h MA stage, only a broad peak of Fe and $\mathrm{Cr}$ is observed. Furthermore, the peaks of the $\mathrm{Fe}$ and $\mathrm{Cr}$ disappear, and an amorphous-like broad pattern occurs

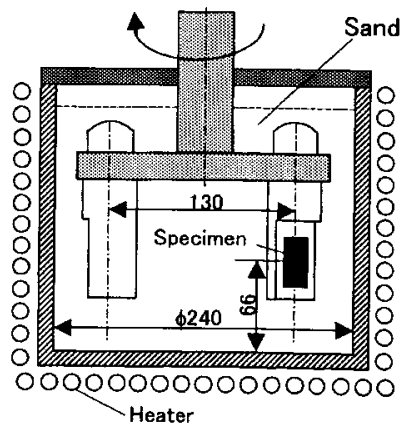

(a)

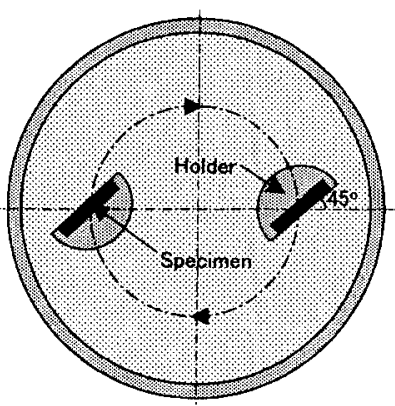

(b)
Fig.2 Schematic view of high temperature abrasion tester: (a) vertical section of the tester, (b) cross section of the specimen holder. after a 200-h MA process.

Fig. 4 shows the appearances of the MA powders after a 200-h MA process and the mixed powder. The MA powders exhibit the peculiar surface to mechanical alloying, i.e., the trace by which pulverization and adhesion were repeated is observed. Although the shape of the MA powder without the $\mathrm{Al}_{2} \mathrm{O}_{3}$ particle is relatively rounded, that of the MA powder with $30 \mathrm{vol} . \% \mathrm{Al}_{2} \mathrm{O}_{3}$ addition is sharp, because the addition of the $\mathrm{Al}_{2} \mathrm{O}_{3}$ powder suppresses the re-adhesion of pulverized powder. The particle sizes of the MA powders decrease with increasing $\mathrm{Al}_{2} \mathrm{O}_{3}$ content, and the particle size tends to be classified into two sizes, fine particle and coarse one. The particle size of the MA powder of $V_{f}=0 \%$ is in the range of $10-30 \mu \mathrm{m}$, and the average particle diameter is $20 \mu \mathrm{m}$. The particle size of the MA powder containing $30 \mathrm{vol} . \% \mathrm{Al}_{2} \mathrm{O}_{3}$ is distributed over the range of $3-20 \mu \mathrm{m}$, and the average particle diameter is $6 \mu \mathrm{m}$.

Fig. 5 shows the microstructures of the test materials. Compared with the conventionally solidified $36 \mathrm{Cr}$ and $25 \mathrm{Cr}$ ingots which have respectively typical eutectic and hypoeutectic microstructures, the MA materials exhibit an extremely refined microstructure. In the composite specimens, the $\mathrm{Al}_{2} \mathrm{O}_{3}$ powder is homogenously dispersed, and no obvious defects have been found in each of the MA specimens.

Fig. 6 shows the Vickers hardness of the test specimens as a function of the testing temperature. All the MA materials are harder than the conventionally solidified $36 \mathrm{Cr}$ ingot at each test temperature. The increase in the $\mathrm{Al}_{2} \mathrm{O}_{3}$ content considerably increases the hardness of the composite materials. At $1073 \mathrm{~K}$, the hardness of the

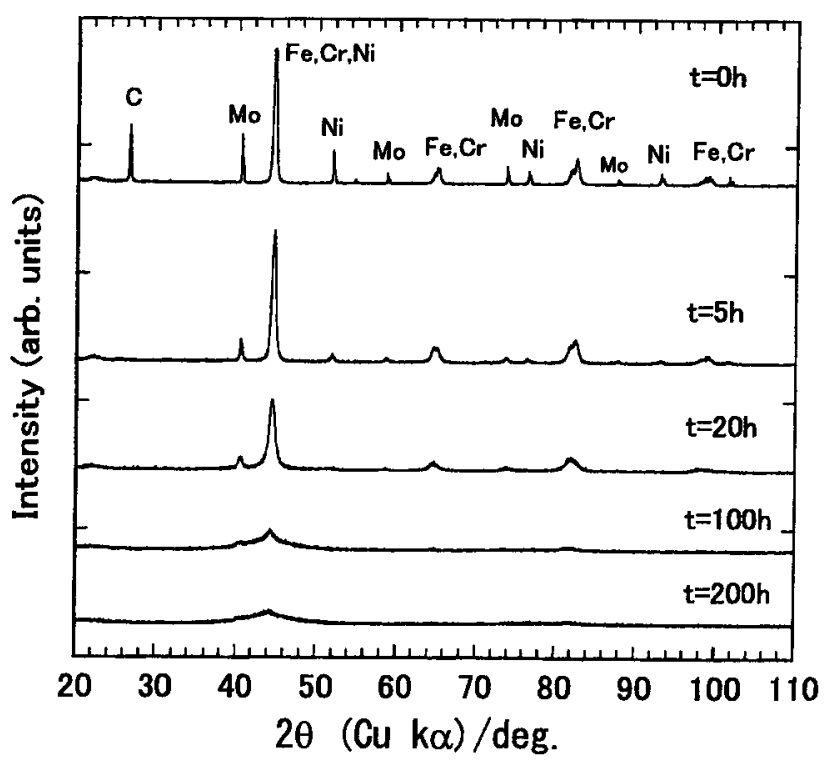

Fig.3 XRD patterns of element powders at various MA times. 


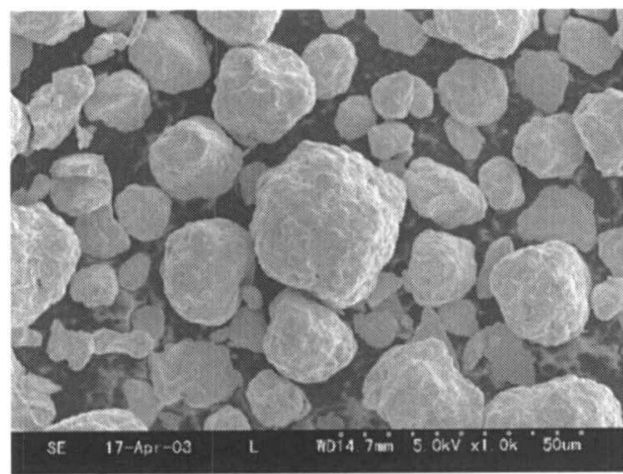

(a) $M A V_{f}=0 \%$

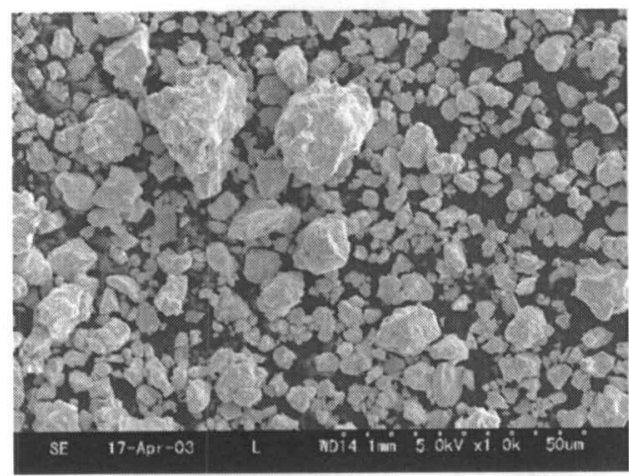

(c) $M A V_{f}=30 \%$

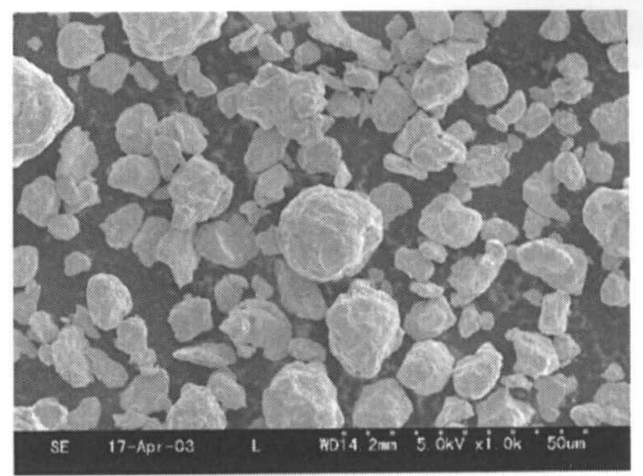

(b) $M A V_{f}=10 \%$

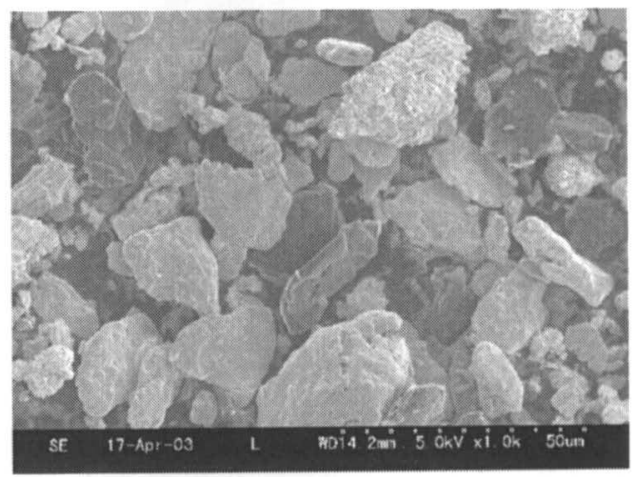

(d) Mixed $V_{f}=0 \%$

$20 \mu \mathrm{m}$

Fig.4 Appearances of MA powders (a, b and c) and mixed one (d).

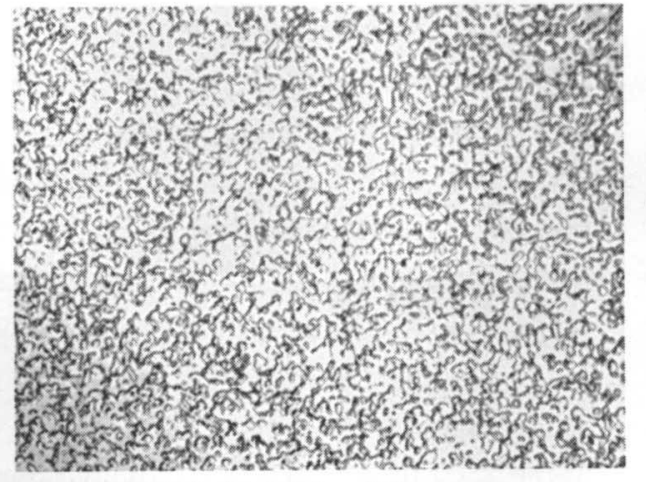

(a) $M A V_{f}=0 \%$

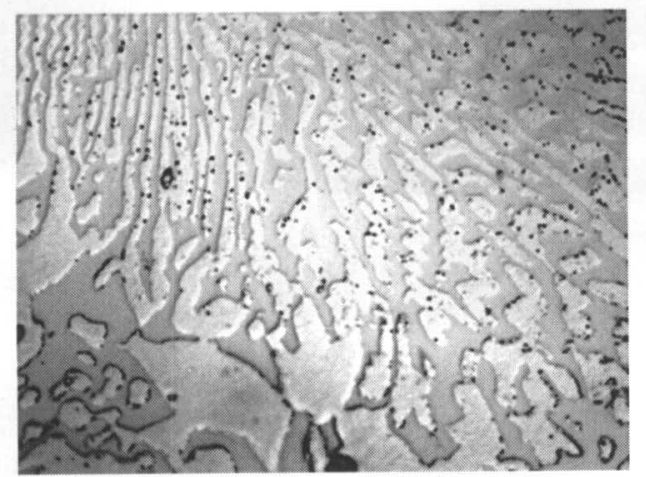

(c) $36 \mathrm{Cr}$ Ingot

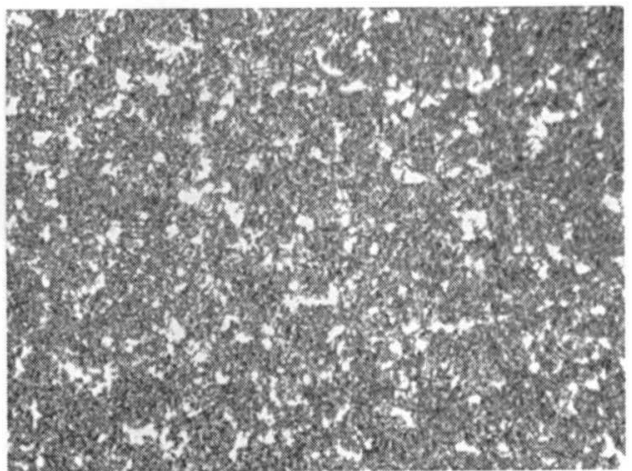

(b) $M A V_{f}=30 \%$

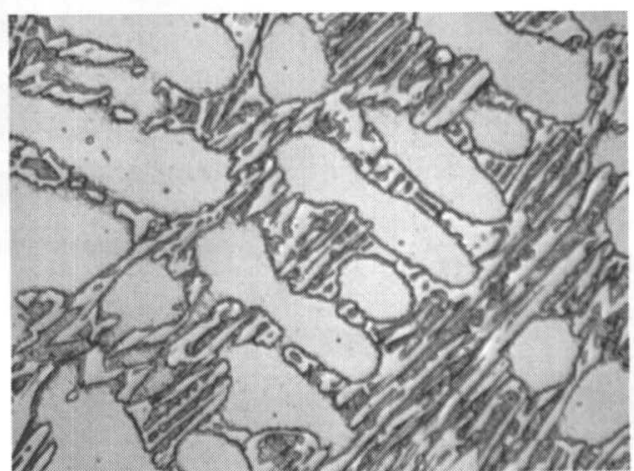

(d) $25 \mathrm{Cr}$ Ingot

Fig.5 Microstructures of MA materials (a and b), $36 \mathrm{Cr}$ ingot (c) and $25 \mathrm{Cr}$ one (d). 


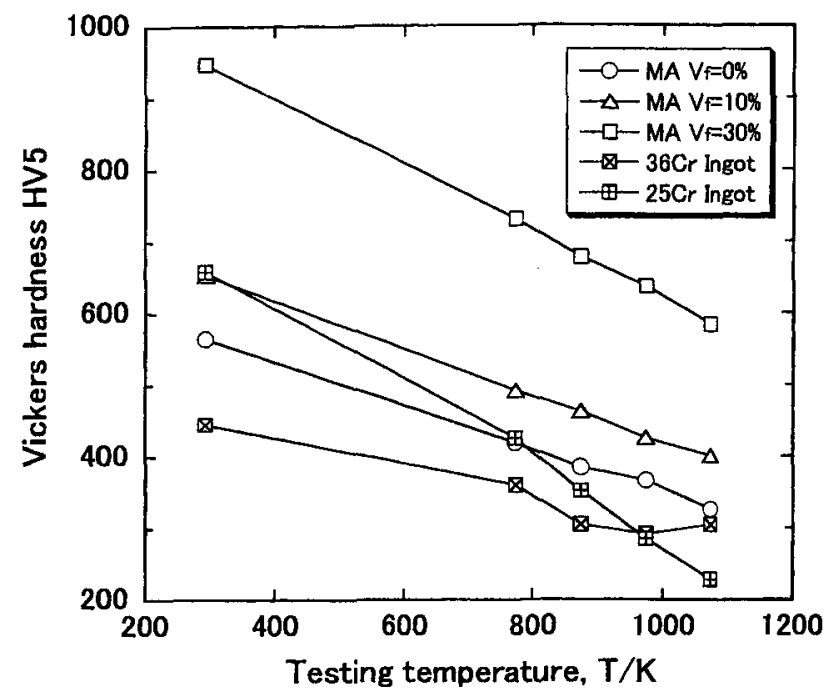

Fig.6 Relationship between Vickers hardness and testing temperature for MA materials, $36 \mathrm{Cr}$ ingot and $25 \mathrm{Cr}$ one.

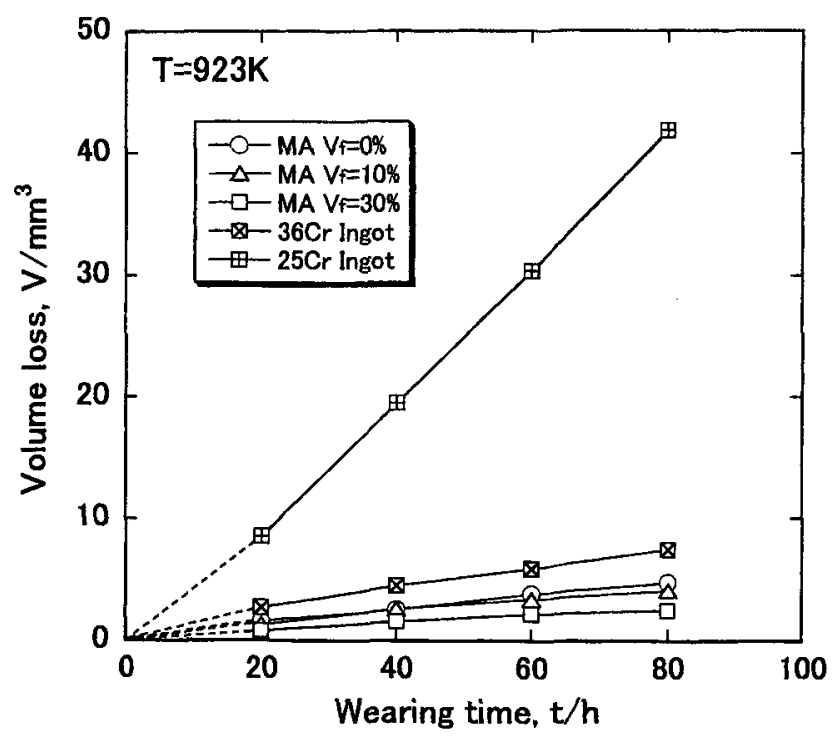

Fig.7 Volume loss as a function of wearing time for MA materials, $36 \mathrm{Cr}$ ingot and $25 \mathrm{Cr}$ one at wearing temperature of $923 \mathrm{~K}$.

composite specimen of $V_{f}=30 \%$ is determined to be 580 HV5 that is equivalent to the RT (room temperature) hardness of the monolithic MA specimen and that is by far greater than the RT hardness of the conventionally solidified $36 \mathrm{Cr}$ ingot.

The volume losses of the specimens in the abrasive test at $923 \mathrm{~K}$ are shown in Fig. 7. The volume losses of the $36 \mathrm{Cr}$ materials prepared by two different processes, conventionally ingot metallurgy and MA-SPS processes, are extremely smaller than that of the $25 \mathrm{Cr}$ ingot, showing the excellent abrasive resistance of the former. Also shown

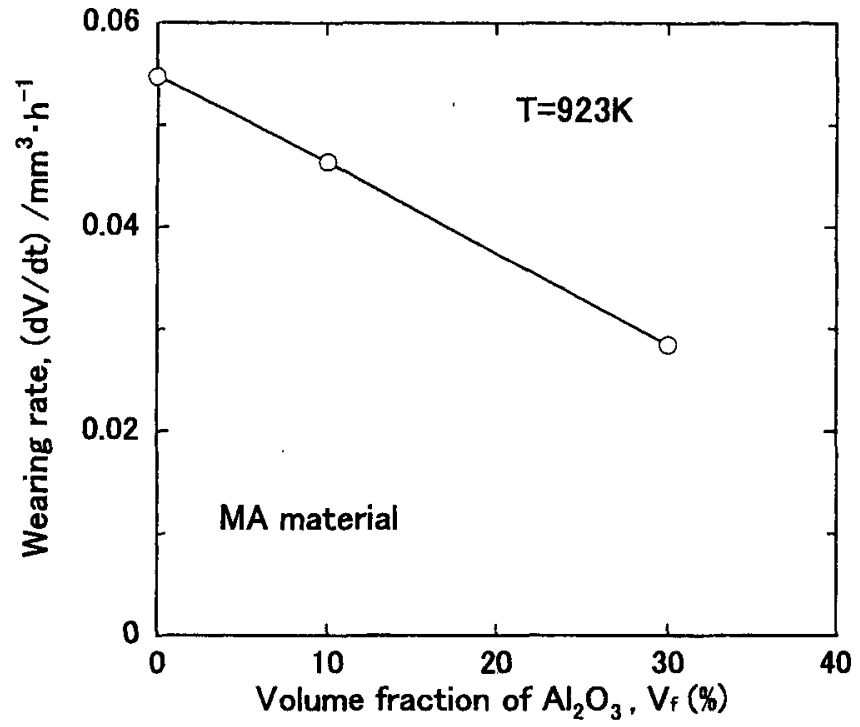

Fig.8 Effect of $\mathrm{Al}_{2} \mathrm{O}_{3}$ content in metallic matrix on wearing rate at wearing temperature of $923 \mathrm{~K}$.

is that the MA process obviously improves the wear resistance of the $36 \mathrm{Cr}$ specimen; the average wear rate (the slope of the curve, $\mathrm{dV} / \mathrm{dt}$ ) of the $36 \mathrm{Cr}$ MA alloy is about $70 \%$ of that of the conventional $36 \mathrm{Cr}$ ingot, i.e., the $\mathrm{MA}$ alloy has 1.4 times higher wear resistance than the $36 \mathrm{Cr}$ ingot. The wear resistance of the composite materials is further improved with increasing content of the $\mathrm{Al}_{2} \mathrm{O}_{3}$ reinforcement. A linear relationship between the wearing rate of the MA materials and the content of the $\mathrm{Al}_{2} \mathrm{O}_{3}$ powder is clearly described in Fig. 8 . The wearing rate of the composite of $V_{f}=30 \%$ is only half of that of the monolithic MA specimen.

Fig. 9 shows the worn surface morphology of the specimens after abrasion at $923 \mathrm{~K}$ for $80 \mathrm{~h}$. The worn surface of the $25 \mathrm{Cr}$ ingot shows a relatively rugged surface, which depends on the microstructure. The primary $\gamma$-phase is worn out more compared with the eutectic phase, because the $\gamma$-phase is softer than the eutectic phase at the test temperature. The $36 \mathrm{Cr}$ ingot also presents a worn surface with the ruggedness, whereas the MA materials have outstanding smooth worn surfaces compared with those of the $25 \mathrm{Cr}$ and $36 \mathrm{Cr}$ ingots. The composite specimen of $\mathrm{V}_{\mathrm{f}}$ $=30 \%$ exhibits an extremely smooth and refined surface.

\section{Conclusions}

The MA-SPS process and the composite technique have been used to further improve the high temperature properties of a newly developed $36 \mathrm{Cr}$ white cast iron. The following conclusions can be drawn from this work: 


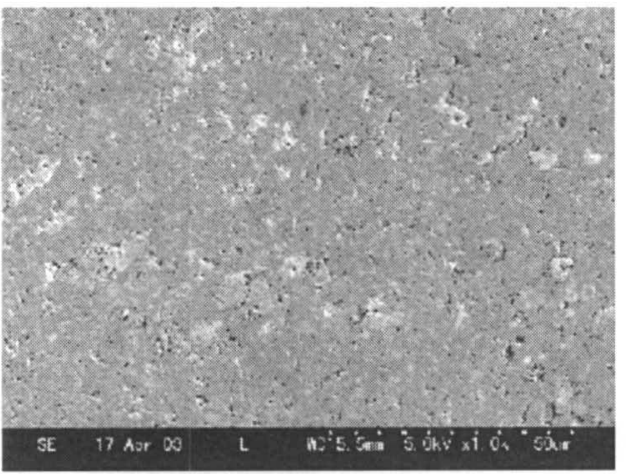

(a) $M A V_{f}=0 \%$

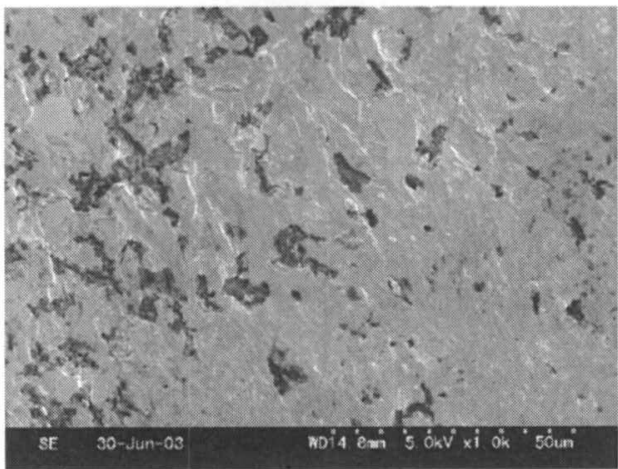

(c) $36 \mathrm{Cr}$ Ingot

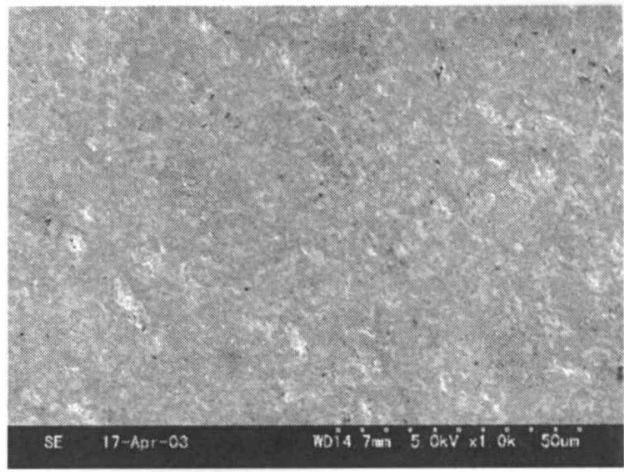

(b) $M A V_{f}=30 \%$

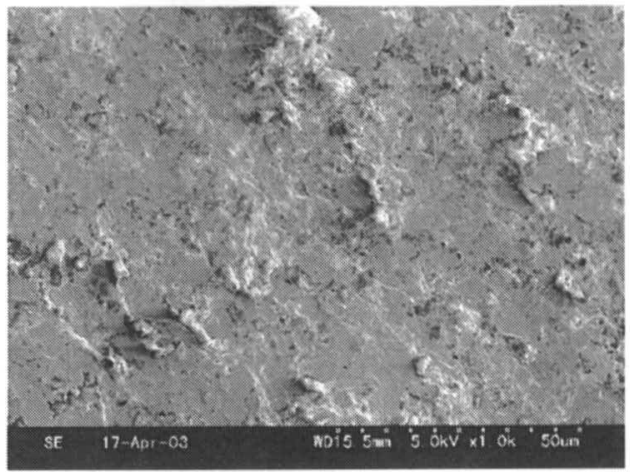

(d) $25 \mathrm{Cr}$ Ingot

$\overline{20 \mu \mathrm{m}}$

Fig.9 Worn surfaces of MA materials (a and b), $36 \mathrm{Cr}$ ingot (c) and $25 \mathrm{Cr}$ one (d) after wearing at $923 \mathrm{~K}$ for $80 \mathrm{~h}$.

(1) The monolithic $36 \mathrm{Cr}$ MA material prepared by the MASPS process is by far harder than the conventionally solidified $36 \mathrm{Cr}$ ingot at each test temperature. The hardness of the MA material can be further improved by forming a composite of it with the $\mathrm{Al}_{2} \mathrm{O}_{3}$ powder. The higher the content of the $\mathrm{Al}_{2} \mathrm{O}_{3}$ powder, the greater is the high temperature hardness of the composite materials.

(2) At the test temperature of $923 \mathrm{~K}$, the monolithic $36 \mathrm{Cr}$ MA material exhibits greater abrasive resistance than the conventionally solidified $36 \mathrm{Cr}$ ingot. The wear rate of the former is only $70 \%$ of that of the latter. The composite process further improves the high temperature abrasive resistance of the $36 \mathrm{Cr}$ MA material. The wear rates of the composites decrease linearly with increasing $\mathrm{Al}_{2} \mathrm{O}_{3}$ content.
(3) The $36 \mathrm{Cr}$ composite material containing 30 vol. $\% \mathrm{Al}_{2} \mathrm{O}_{3}$ exhibits the remarkably smooth and refined worn surface compared to the $25 \mathrm{Cr}$ and $36 \mathrm{Cr}$ ingots after the abrasion test for $80 \mathrm{~h}$.

\section{References}

1) C.P.Tong, T.Suzuki and T.Umeda: "High Chromium Cast Iron Rolls for Steel Rolling Mills", J. of Japan Foundry Eng. Soc., 62(1990)925-932.

2) S.Sakamoto, S.Akiyama, T.Satoh, A.Kitahara, K.Ogi and M.Nomura: Japanese Patent, Patent No. 3434496, (May 30, 2003).

3) H.N.Liu, M.Sakamoto, M.Norura and K.Ogi: "Abrasion Resistance of High Cr Cast Iron at an Elevated Temperature", Wear, 250(2001)71-75. 